\title{
Quantitative Secretomic Analysis Identifies Extracellular Protein Factors that Modulate the Metastatic Phenotype of Non-Small Cell Lung Cancer
}

\author{
Rongkuan $\mathrm{Hu}^{1}$, Kenneth E. Huffman ${ }^{2}$, Michael Chu ${ }^{1}$, Yajie Zhang ${ }^{1}$, John D. Minna ${ }^{2}$, and \\ Yonghao $\mathrm{Yu}^{1}{ }^{1}$, \\ ${ }^{1}$ Department of Biochemistry, University of Texas Southwestern Medical Center, Dallas, Texas, \\ USA \\ ${ }^{2}$ Hamon Center for Therapeutic Oncology Research, Simmons Comprehensive Cancer Center, \\ Pharmacology and Internal Medicine, University of Texas Southwestern Medical Center, Dallas, \\ Texas, USA
}

\section{Abstract}

Lung cancer is the leading cause of cancer-related deaths for men and women in the United States, with non-small cell lung cancer (NSCLC) representing 85\% of all diagnoses. Late stage detection, metastatic disease and lack of actionable biomarkers contribute to the high mortality rate. Proteins in the extracellular space are known to be critically involved in regulating every stage of the pathogenesis of lung cancer. To investigate the mechanism by which secreted proteins contribute to the pathogenesis of NSCLC, we performed quantitative secretomic analysis of two isogenic NSCLC cell lines (NCI-H1993 and NCI-H2073) and an immortalized human bronchial epithelial cell line (HBEC3-KT) as control. H1993 is derived from a chemo-naïve metastatic tumor while H2073 was derived from the primary tumor after etoposide/cisplatin therapy. From the conditioned media of these three cell lines, we identified and quantified 2713 proteins. Gene Ontology (GO) analysis indicates that a number of proteins overexpressed in H1993 media are involved in biological processes related to cancer metastasis, including cell motion, cell-cell adhesion and cell migration. RNA interference (RNAi)-mediated knock down of a number of these proteins, including SULT2B1, CEACAM5, SPRR3, AGR2, S100P and S100A14, leads to dramatically reduced migration of these cells. In addition, meta-analysis of survival data indicates NSCLC patients whose tumors express higher levels of several of these secreted proteins, including SULT2B1, CEACAM5, SPRR3, S100P and S100A14, have a worse prognosis. Collectively, our results provide a potential molecular link between deregulated secretome and NSCLC cell migration/metastasis. In addition, the identification of these aberrantly secreted proteins might facilitate the development of biomarkers for early detection of this devastating disease.

\section{Graphical Abstract}




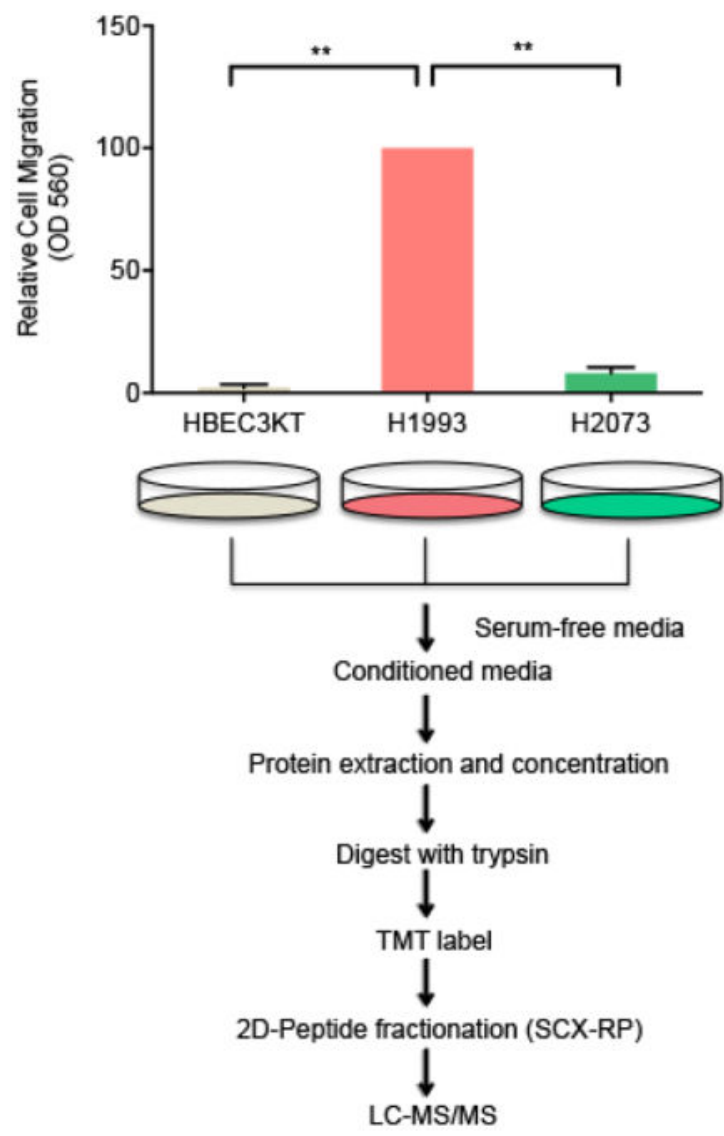

\section{Keywords}

secretome; non-small cell lung cancer; metastasis; proteomics and mass spectrometry

\section{Introduction}

Cancers of the lung and bronchus are a set of devastating diseases, which kill 159,260 Americans in 2014(1). Based on etiological and pathological differences, lung cancer can be divided into two major histotypes, namely non-small cell lung cancer (NSCLC) and smallcell lung cancer (SCLC)(2). Within the NSCLC group, it can be further subtyped into adenocarcinoma, squamous cell carcinoma and large cell carcinoma(3). Adenocarcinoma is the most common form of lung cancer, which accounts for nearly $40 \%$ of all lung cancer cases(4). A high degree of heterogeneity is noted in adenocarcinoma as large scale genomic sequencing efforts have identified distinct "driver mutations", including those of the epidermal growth factor receptor (EGFR), KRas, STK11, and $A L K$, etc(5-8). Lung adenocarcinoma has a very poor prognosis, with a 5 -year survival rate of about $15 \%(9)$. This is mainly due to late-stage detection and a paucity of therapies that are effective against metastatic diseases. 
Approximately $15 \%$ of the human genome encodes proteins that are targeted to the extracellular space(10). They can be released from a cell through a number of mechanisms. For example, soluble proteins can be secreted by exocytosis of secretory vesicles or storage granules(10). Alternatively, the ectodomain of a plasma membrane-bound protein can be shed, which generates free fragments of the parent protein(11). In addition, recent evidence has pointed out that proteins can also be exported through ER/Golgi-independent pathways, i.e. the so-called non-classical secretory mechanism(12).

Aberrant secretion or shedding of proteins is intimately linked to the tumorigenesis of lung cancer. It is now widely appreciated that the initiation and progression of NSCLC is not merely a cell-autonomous process that is confined to the cancer cell itself. Rather, the pathogenic signaling pathways also involve dynamic cross talk between the tumor cells and their microenvironment(13). This bi-directional information flow at the tumor-host interface is particularly relevant in the metastatic setting, where extensive tissue remodeling and tumor adaptation occur. These biological processes are often orchestrated by secreted signaling proteins, such as those involved in intravasation/extravasation, immunomodulation and matrix degradation(14). In addition, proteins originating from the tumor itself or its adjacent cells could enter systemic circulation. It is conceivable that these secreted proteins might serve as potential biomarkers for early detection and monitoring therapeutic effectiveness for NSCLC.

Routine analysis of secreted proteins, however, is challenged by a number of technical difficulties. Many extracellular proteins are expressed at exceedingly low levels and can be easily masked by high concentration serum proteins that are present in the culture media. Culturing cells in serum-free media (SFM) offers a solution to this problem allowing for easy recovery of secreted proteins without complications arising from non-human contaminants. For example, Chenau used mass spectrometry-based proteomic approaches and characterized the conditioned media (CM) of a p53-deficient NSCLC line, H358, and its derivative that was reconstituted with wild-type p53. In total, they were able to identify 1430 proteins from these CM samples, 91 of which seemed to be regulated in a p53-dependent manner(15).

Despite recent progress, our understanding of how the secretome is remodeled during the progression of lung cancer is still poor. To address this question, we investigated three cell lines, namely, HBEC3-KT, H1993 and H2073. HBEC3-KT is a non-tumorigenic, immortalized human bronchial epithelial cell line that is immortalized by the introduction of CDK4 and hTERT(16, 17). The choice of H1993 and H2073 is important because they are derived from the same lung adenocarcinoma patient and represent both metastatic and primary tumor sites, allowing us to analyze the secretome from different anatomical microenvironments. Specifically, H1993 was a metastatic cell line established from the initial diagnostic biopsy from a mediastinal lymph node. The patient then received 8 weeks of neoadjuvant chemotherapy with etoposide and cisplatin $(18,19)$. The patient responded to therapy with tumor shrinkage and then had a pulmonary resection to remove the primary tumor, from which the $\mathrm{H} 2073$ cell line was derived. We reason that a quantitative analysis of the secretome associated with these three cell lines will provide a stage-specific map of the extracellular proteins that are important for the oncogenesis and metastasis of NSCLC. 


\section{Experimental Procedures}

\section{Materials}

PET track-etched membrane ( 6 well, $8.0 \mu \mathrm{m}$ ) was purchased from Corning. AGR2 and GAPDH antibodies were purchased from Cell Signaling Technology and Santa Cruz Biotechnology, respectively. RNAiMAX, Keratinocyte-SFM, Bovine Pituitary Extract (BPE) and Epidermal Growth Factor (EGF) were purchased from Life Technologies. RPMI-1640, Fetal Bovine Serum (FBS), siRNAs were purchased from Sigma-Aldrich.

\section{Cell culture}

All lung cell lines used in this study were obtained from the Hamon Cancer Center Collection (University of Texas Southwestern Medical Center, Dallas, TX). HBEC3-KT cells were cultured in Keratinocyte-SFM (GIBCO) supplemented with BPE and EGF (GIBCO) at $37{ }^{\circ} \mathrm{C}$ in $5 \% \mathrm{CO}_{2}$. $\mathrm{H} 2073$ and $\mathrm{H} 1993$ cells were cultured in RPMI-1640 (Sigma) with $10 \%$ FBS (Sigma) at $37^{\circ} \mathrm{C}$ in $5 \% \mathrm{CO}_{2}$. All cell lines have been DNA fingerprinted using the PowerPlex 1.2 kit (Promega) and are found mycoplasma free using the e-Myco kit (Boca Scientific).

\section{Transfection with small interfering RNA}

H1993 cells cultured in 6-well plates were transfected with small interfering RNAs (siRNAs) using RNAiMAX (Invitrogen). After overnight transfection, media was changed. The cells were lysed after 48 hours for further analysis(20).

\section{Western blotting analysis}

Cells were harvested and lysed in SDS lysis buffer (1\% SDS, 10mM HEPES, pH7.0, 2mM

$\mathrm{MgCl}_{2}$, universal nuclease $20 \mathrm{U} / \mathrm{ml}$ ). Total cellular protein concentration was measured by the BCA assay kit (Thermo Fisher Scientific). Equal amounts of the protein samples were subjected to 10\% SDS-PAGE and transferred to nitrocellulose blotting membranes (GE Healthcare). The membranes were then blotted with primary antibodies overnight at $4{ }^{\circ} \mathrm{C}$, which is followed by incubation with the secondary antibody for $1 \mathrm{~h}$ at room temperature. Proteins were developed using enhanced chemiluminescence exposed on autoradiograph film and developed using standard methods previously described(21).

\section{Cell migration assay}

Cell migration assay was performed using cell culture inserts with $8.0 \mu \mathrm{m}$ PET track-etched membrane (Corning). After transfected with siRNAs, cells were serum starved for 24 hours and then seeded into the upper chamber of the insert $\left(2 \times 10^{5}\right.$ cells/well $)$ in serum free media. The lower chamber was filled with media containing 10\% FBS. After 48 hours, cells were fixed using pre-chilled methanol and stained using $0.5 \%$ crystal violet. Cells in upper chamber were carefully removed and cells migrated through the membrane were photographed. For quantification, crystal violet was dissolved with 33\% acetic acid and the absorbance at $560 \mathrm{~nm}$ was measured(22). 


\section{Secretome sample preparation for mass spectrometric analysis}

Cells were starved in serum free media for 24 hours, and the conditioned media (CM) was centrifuged (2000 rpm, $3 \mathrm{~min}$ ), filtered ( $0.45 \mu \mathrm{M}$ Polythersulfone Membrane, GE healthcare) and lyophilized. We performed two biological analyses for each CM sample (see below for the detailed description of the TMT experiments). Secreted proteins were subjected to methanol/chloroform precipitation (methanol: chloroform: $\mathrm{H}_{2} \mathrm{O}$ : sample $=4: 1: 3: 1$ ) and subsequent ice cold methanol washes. Protein pellets were re-solubilized in a freshly prepared $8 \mathrm{M}$ urea buffer (containing $50 \mathrm{mM}$ Tris, $10 \mathrm{mM}$ EDTA, pH 7.5) and concentrations were measured by the BCA assay (Thermo Scientific). Proteins were reduced (2 mM DTT for $15 \mathrm{~min}$ at RT) and alkylated ( $30 \mathrm{mM}$ iodoacetamide for $30 \mathrm{~min}$ at RT). Proteins were digested by Lys-C at a 1:100 enzyme/protein ratio for 2 hours, and then digested by trypsin at a 1:100 enzyme/protein ratio overnight at RT. Peptides were desalted by using Oasis HLB solid-phase extraction (SPE) cartridges (Waters)(23).

Desalted peptides were resuspended in $200 \mathrm{mM}$ HEPES pH 8.5. Approximately $100 \mu \mathrm{g}$ peptides were reacted with the amine-based TMT six-plex reagents (Thermo Fisher) for 1 hour at room temperature (We performed two biological replicate analysis for each condition, i.e. 126 and 127 for HBEC3-KT CM; 128 and 129 for H1993 CM; and then 130 and 131 for $\mathrm{H} 2073 \mathrm{CM}$ ). Hydroxylamine solution was added to quench the reaction and the labeled peptide samples were combined. The TMT sample was lyophilized and reconstituted in $400 \mu \mathrm{l}$ buffer $\mathrm{A}\left(5 \mathrm{mM} \mathrm{KH}_{2} \mathrm{PO}_{4}, \mathrm{pH} 2.65,30 \%\right.$ acetonitrile). It was then centrifuged at $10,000 \mathrm{rpm}$ for 3 minutes using spin-X centrifuge tube filters (Corning) prior to loading onto a SCX column (PolySULFOETHYL A ${ }^{\mathrm{TM}}, 200 \mathrm{~mm} \times 4.6 \mathrm{~mm}, 5 \mu \mathrm{m}$ particle size, $200 \AA ̊$ pore size, PolyLC). Peptides were fractioned by SCX-HPLC at a flow rate of $1 \mathrm{ml} / \mathrm{min}$. Gradient was developed from $0 \%$ to $21 \%$ buffer $\mathrm{B}\left(5 \mathrm{mM} \mathrm{KH}_{2} \mathrm{PO}_{4}, \mathrm{pH} 2.65,30 \%\right.$ acetonitrile, 350 $\mathrm{mM} \mathrm{KCl})(20)$. Twenty fractions were collected, which were lyophilized, desalted and analyzed by LC-MS/MS.

\section{LC-MS/MS analysis}

The TMT sample was analyzed by LC-MS/MS on an LTQ Velos Pro Orbitrap mass spectrometer (Thermo, San Jose, CA) using a top ten HCD (higher-energy collisional dissociation) method. Peptides were separated on a hand-pulled fused silica microcapillary ( $75 \mu \mathrm{M} \times 15 \mathrm{~cm}$, packed with Magic C18AQ, Michrom Bioresources, Auburn, CA) using a 75 min linear gradient ranging from $7 \%$ to $32 \%$ acetonitrile in $0.1 \%$ formic acid at 300 $\mathrm{nL} / \mathrm{min}$ (Thermo EASY-nLC system). Orbitrap resolution for precursor and fragment ions was set to be 60000 and 7000 , respectively. The isolation window, minimal signal threshold and normalized collision energy were set to be 2 Th, 500 and 34, respectively. For MS2 experiments, precursor ions with 1+ or unassigned charge states were rejected. Dynamic exclusion was enabled in which the same precursor ion was excluded from repeated MS2 analyses for $60 \mathrm{sec}$.

MS/MS spectra were searched against a composite database of the human IPI protein database (Version 3.60, which contains a total of 80,412 entries) and its reversed complement using the Sequest (Rev28) algorithm. Search parameters allowed for a static modification of 57.02146 Da, 229.16293 Da, 229.16293 Da for Cys, Lys, and peptide N- 
terminus, respectively. A dynamic modification of oxidation (15.99491 Da) was considered for Met. Search results were filtered to include $<1 \%$ matches to the reverse data base by the linear discriminator function using parameters including Xcorr, $\mathrm{dCN}$, missed cleavage, charge state (exclude 1+ peptides), mass accuracy, peptide length and fraction of ions matched to MS/MS spectra.

Protein TMT ratios were determined using the procedure as described previously(24). Specifically, a $0.03 \mathrm{Th}$ window was scanned around the theoretical $\mathrm{m} / \mathrm{z}$ of each reporter ion (126: 126.127725; 127: 127.124760; 128: 128.134433; 129: 129.131468; 130: 130.141141; 131: 131.138176) to detect the presence of these ions, and the maximum intensity of each ion is extracted. The $\mathrm{SN}$ value of each protein is calculated by summing the reporter ion counts (SN) across all identified peptides, which is exported for further analysis in Excel. Because a same amount of peptides was used for each TMT channel, the total reporter ion intensity of each channel was summed across all quantified proteins, and was normalized.

In order to present the data in an unbiased manner (maximal presentation of all the data), a protein is identified once it passes the FDR filtering (this is also due to the nature of the TMT experiment, i.e. identified for all six samples/channels). We present the quantitative information as a way of showing their differential expression among the three cell lines (rather than showing the difference at the protein identification level).

\section{Relative protein expression based clustering}

The signal to noise ratio ( $\mathrm{SN}$ ) of a protein was determined by summing the corresponding values for its individual peptides. These protein $\mathrm{SN}$ values were further processed and compared among the three cell lines based using the following criteria: $\mathrm{x}=\mathrm{SN}_{\text {cell line } \# 1 \text { / }}$ Max SN (the other two cell lines). For example, the SN of MUC1 in HBEC3-KT, H2073 and H1993 was determined to be 33, 63 and 706 respectively. The degree of overexpression of MUC1 in H1993 $=\mathrm{SN}_{\mathrm{H} 1993} / \mathrm{Max} \mathrm{SN}_{(\mathrm{H} 2073 \text { and HBEC3-KT })}=706 / 63=11.2$. These values were then transformed to a $\log 2$ base (i.e. $y=\log _{2}(\mathrm{x})$ ). $\mathrm{Y}$ values were grouped via hierarchical clustering (Euclidean distance, single linkage) using Cluster 3.0. Results were visualized using Java TreeView. Selected proteins were analyzed by gene-ontology (GO) using the DAVID database.

\section{Results}

\section{Selection of cell lines, and their phenotypic characterization}

We sought to quantitatively analyze the secretome of cell lines that serve to model the three basic stages of lung cancer progression, i.e. immortalization, tumorigenesis and metastasis. HBEC3-KT is an immortalized cell line characterized by a number of properties consistent with untransformed epithelial cells, including: (1) normal epithelial morphology, (2) expression of epithelial markers, (3) lacking anchorage-independent growth and (4) inability to form tumors in vivo $(16,17,25,26)$. As expected, HBEC3-KT cells are unable to cross a porous polyethylene terephthalate (PET) membrane in a transwell assay (Figure 1).

Interestingly, although H1993 and H2073 cells are isogenic, they display a striking difference in their migration potential. H1993 cells, but not H2073 cells, are known to 
harbor c-Met amplification, an oncogene that is critically involved in regulating invasive growth(18). In keeping with previous reports(27), we also found that, compared to H2073, metastasis-derived H1993 cells have a much greater migration capacity in transwell assays (Figure 1).

\section{A mass spectrometry-based quantitative secretomic platform}

We starved the three cell lines in serum-free media (SFM), and collected their conditioned media after 24 hours. We considered variables including seeding density, incubation time and media volume, in order to achieve the optimal growth/collection conditions. A schematic of the quantitative secretomic platform is shown in Figure 2A. Briefly, the same amounts of CM proteins were collected from the three cell lines. The samples were lyophilized, and proteins were extracted by methanol/chloroform precipitation. Proteins were trypsin digested and were subsequently labeled with a 6-plex TMT reagent. For this experiment, we included two biological replicate analyses for each cell line, i.e. channel 126 and 127 for HBEC3-KT, 128 and 129 for H1993, and then 130 and 131 for H2073 cells. Correlation analysis indicates that we achieved an excellent reproducibility in TMT quantification between the biological replicate samples (Figure 2B).

One major challenge associated with secretomic analysis is the potentially large dynamic range for detected proteins. To facilitate deep sequencing of these secreted proteins, the pooled peptides were subject to off-line two-dimensional SCX-RP (strong cation exchangereverse phase) HPLC separation. In the first dimension, peptides were separated based on their in-solution charges using an SCX column. Twenty fractions were collected, which were lyophilized individually, and were subject to a second dimension of RP separation. Peptides were analyzed by MS and MS/MS experiments on a Thermo LTQ Velos Pro Orbitrap mass spectrometer.

\section{Identification of secreted proteins from normal/NSCLC cells}

From the abovementioned TMT-labeled CM sample, we were able to identify and quantify a total of 58599 peptides from 2713 proteins (peptide false discovery rate $=0.45 \%$ ). This list contains many well-known extracellular proteins. For example, HSPG2, LAMA5 and AGRN, three major components of the extracellular matrix(28), were identified with sequence coverage of 58\%, 49\% and 56\%, respectively. In addition, this list contains many secreted signaling molecules that are known to be expressed at low levels, including growth factors (HBEGF, IGF2, HDGF, TGFB3, HDGF2, TGFB1, VEGFC, TGFB2, PDGFC, CTGF, TGFBI) and chemokines/cytokines (CXCL1, CXCL2, IL11 and IL18).

In order to more comprehensively evaluate the dataset, we sorted the 2713 proteins based on the signal-to-noise ratios of their TMT reporter ions (summed over all channels for all peptides), and selected proteins with a summed TMT SN of at least 10000 (a total of 328 proteins). Gene Ontology (GO) analysis of these proteins show that they are highly enriched in the extracellular component $\left(\mathrm{p}=2.9 \times 10^{-25}\right)$ and membrane-bound vesicles $(\mathrm{p}=7.6 \times$ $10^{-15}$ ) (Fig 3A). These proteins are involved in a number of biological processes linked to extracellular matrix biology, including inflammatory response $\left(\mathrm{p}=5.4 \times 10^{-10}\right)$, regulation of programmed cell death $\left(\mathrm{p}=1.8 \times 10^{-8}\right)$ and cell motion $\left(\mathrm{p}=1.8 \times 10^{-8}\right)$ (Figure 3B). 
Previously, Chenau et al. used LC-MALDI-MS/MS experiments, and identified 1430 proteins from the CM of an NSCLC cell line derived from a primary tumor, NCI-H358(15). Cross-reference analysis with our results indicates that there is a substantial overlap in the two datasets, with 458 proteins commonly identified by both studies (Figure 3C). At the same time, there are also distinct proteins that appear to be secreted by specific NSCLC cell lines. For example, we identified a number of proteins that are unique to HBEC3-KT/ H1993/H2073 cells, including mucin-1 (MUC1) and carcinoembryonic antigen-related cell adhesion molecule 5 (CEACAM5). These two molecules both contain an N-terminal signal peptide specific for proteins targeted to the secretory pathway (Figure 3D). MUC1 is a transmembrane glycoprotein in the mucin family that is known to line the apical surface of epithelial cells in the lungs, intestines and several other organs(29). In lung cancer studies, MUC1 has been shown to be overexpressed in a subpopulation of NSCLC patients(30). The ectodomain of MUC1 interacts with its ligand galectin-3, which triggers further complexation with EGFR, and EGFR-dependent downstream signaling(31). Similarly, CEACAM5 is a transmembrane glycoprotein that is expressed on epithelial cells. It is upregulated in a wide variety of human cancers, and is known to play a critical role in promoting tumor cell migration, invasion, adhesion and metastasis(32). The identification of MUC1 and CEACAM5 in the CM sample validates our mass spectrometry-based secretomic platform.

\section{Quantification of secreted proteins from normal/NSCLC cells}

We determined the relative protein expression in the $\mathrm{CM}$ from the three cell lines (i.e. HBEC3-KT, H1993 and H2073). For our analysis, the raw TMT ion intensity of a protein in one cell line (SN summed over all peptides in the two replicate samples) was divided by the larger one between the other two corresponding values (from the other two cell lines). The results indicate that a large fraction of the identified proteins are differently regulated among the three normal/NSCLC cells (Figure 4).

Proteins overexpressed in HBEC3-KT CM (compared to H1993 and H2073) are enriched for GO biological processes related to epidermis development $\left(\mathrm{p}=3.8 \times 10^{-8}\right)$ and epidermal cell differentiation $\left(\mathrm{p}=1.3 \times 10^{-3}\right)$. On the other hand, proteins over represented in H2073 (compared to HBEC3-KT and H1993) CM are linked to ovulation cycle ( $\mathrm{p}=6.7 \times$ $\left.10^{-6}\right)$, ossification $\left(\mathrm{p}=9.2 \times 10^{-5}\right)$, gliogenesis $\left(\mathrm{p}=1.3 \times 10^{-4}\right)$ and response to hormone stimulus $\left(\mathrm{p}=6.0 \times 10^{-4}\right)$. Most intriguingly, proteins upregulated in H1993 (compared to HBEC3-KT and H2073) CM are involved in many biological processes related to cancer metastasis, including cell adhesion $\left(\mathrm{p}=2.9 \times 10^{-6}\right)$, cell motion $\left(\mathrm{p}=7.7 \times 10^{-4}\right)$, extracellular structure organization and cell migration $\left(\mathrm{p}=8.3 \times 10^{-3}\right)$ (Figure 4).

As one example of the differentially regulated proteins, we highlight AGR2 (anterior gradient protein 2) from which we identified a total of 11 unique peptides (a representative peptide is shown in Figure 5A). AGR2 is a secreted protein that contains a signal peptide in its $\mathrm{N}$ terminus and is expressed in mucinous and endocrine tissues (Figure 5B). AGR2 has been postulated to function as an oncogene that promotes cell growth and migration in various human cancers, including those of esophagus, pancreas, prostate and lung(33-39). We found that AGR2 is dramatically upregulated in H1993 cells, whereas the CM from 
HBEC3-KT and H2073 contains virtually undetectable signals for AGR2 (Figure 5C). Independent immunoblotting experiments confirmed our quantitative mass spectrometry results (Figure 5D).

\section{Functional characterization of secreted proteins overexpressed in metastasis-derived NSCLC cells}

We then focused our analysis on the metastatic setting. Specifically, we extracted protein expression data of H1993 and H2073 cells, and performed a binary analysis. Predictably, most of the proteins were expressed at similar levels in the CM from these isogenic lines. However, a total of 317 proteins are overexpressed by at least 2-fold in H1993 CM as compared to that from H2073 cells (Figure 6A, Table S1). From these, we selected 12 proteins for further functional characterization (Table. 1). These proteins either have an $\mathrm{N}$ terminal signal peptide or have been reported to be cell surface/secreted proteins(40-45). Some of these proteins have also been implicated in cell migration (e.g. AGR2 and CEACAM5)(32, 37).

In order to link these differentially expressed $\mathrm{CM}$ proteins to the metastatic phenotype of NSCLC, we knocked down the 12 proteins in H1993 cells using small-interference RNAs (siRNAs) (Table S2). Remarkably, depletion of 6 out of these 12 proteins led to a significant inhibition of migration of H1993 cells in a transwell assay, including SULT2B1, CEACAM5, SPRR3, AGR2, S100P and S100A14 (Figures. 6B and S1).

Because of their potential connection in regulating the metastasis of NSCLC, we hypothesized that patients with higher expression of some of these 6 proteins (SULT2B1, CEACAM5, SPRR3, AGR2, S100P, S100A14) might have a worse prognosis. Towards this, we performed a survival meta-analysis for the abovementioned 6 candidate metastatic biomarkers. Kaplan-Meier curves for these were generated using the online meta-analysis tool KM Plotter(46). From an analysis of gene expression and clinical data for 1,926 individuals we find that high expression of SULT2B1, CEACAM5, SPRR3, S100P and S100A14 predicts a worse outcome for those patients (Figures 6C, 6D and S2), suggesting a link between expression of members of the metastasis secretome and patient survival.

\section{Discussion}

Tumorigenesis is a complex process beginning with the initial acquisition of genetic damage through its final progression to malignancy. De-regulation of proliferative pathways, evasion of senescence and apoptosis, induction of angiogenesis and modulation of host immune responses are all part of oncogenic progression and are affected not only by the cancer cells themselves, but also by the tissue microenvironment they are embedded in(47).

Macromolecular communication between tumor and stroma play a significant role in all of the aforementioned pathways to progression(48). Accumulated evidence has pointed to the indispensable role played by secreted proteins in almost every aspect of the oncogenesis of NSCLC, in particular, those relevant to metastasis(49). Identification of secretome components that are functionally relevant in these processes will greatly facilitate the understanding of NSCLC biology. Equally important, secreted proteins may represent a class of systemic biomarkers for detection and monitoring of metastatic disease(50). 
Towards this end, a number of studies have been carried out with the aim of generating a comprehensive catalogue of the proteins that are secreted by NSCLC cells. For example, using SWATH- and ITRAQ based proteomic technologies, Zhang et al. found that CD109 is involved in the regulation of malignant phenotypes in lung cancer cells(51). Chenau et al. previously investigated how $\mathrm{p} 53$, a major tumor suppressor, modulates the secretome of NSCLC cells(15). In another study, Planque et al. used a two-dimensional LC-MS/MS strategy, and identified a total of 1830 proteins in CM from lung cancer cell lines of four different histological backgrounds (i.e. adenocarcinoma/NSCLC, squamous cell carcinoma/ NSCLC, large cell carcinoma/NSCLC, and small cell lung cancer)(52). Finally, Chang et al., combined a hollow fiber culture (HFC) system with label-free proteomics to analyze proteins that are differentially secreted between CL 1-0 and CL 1-5 (two NSCLC lines with low and high metastatic potentials, respectively). They identified PARK7 (protein deglycase DJ-1) as one of the differentially expressed proteins. Importantly, cell proliferation, migration and invasion properties were greatly diminished when PARK7 was reduced, suggesting that is intimately involved in promoting the progression of lung adenocarcinoma(49).

Compared to these prior studies, our approach offers several distinct advantages. First, we chose cell lines designed to model the basic stages of lung adenocarcinoma development, including immortalization of normal cells (HBEC3-KT), primary (H2073) and metastatic tumor (H1993). HBEC3-KT cells provide a benchmark for the proteins that are secreted under basal conditions, whereas the isogenic H1993 and H2073 lines offer the opportunity of identifying secreted proteins relevant to the metastatic setting. We highlight the fact that use of a primary and metastatic cell line from the same patient may allow for the identification of more secretome level distinctions by reducing the signal noise associated with inter-individual comparisons. Because $\mathrm{H} 2073$ cells were established from the primary tumor after the patient had received neoadjuvant chemotherapy, there is a possibility that these proteomic changes might have been due to the selection of a subpopulation of tumor cells by chemotherapy. Nevertheless, mutation analyses indicate that these two cell lines have the exact same mutations in p53, STK11 as well as other genes(19), suggesting that they were derived from the same primary tumor. In addition, a number of secreted proteins are drastically overexpressed in H1993 cells, many of which are related to biological processes implicated in cancer metastasis (e.g. cell adhesion and extracellular structure organization, see Figure 4), rather than drug resistance. Further functional studies indicate that at least some of them are indeed involved in regulating the migration of H1993 cells, suggesting that they are more linked to the metastatic phenotype of this cell line.

Second, we fractionated the peptides using a 2D-SCX-RP-LC system, in order to overcome the dynamic range issue associated with secretomic analysis. Indeed, even though we used a relatively slow MS/MS fragmentation method (i.e. HCD on an LTQ Velos Orbitrap mass spectrometer, in order to be compatible with TMT-based quantification), we were still able to identify 2713 proteins in the CM of these three cell line (Table S3, S4 and S5). This list, to our knowledge, is one of the largest repositories of secreted proteins identified for lung cancer. They include many signaling molecules that are known to be expressed at low levels, including growth factors, chemokines and cytokines. Remarkably, 458 out of these 2713 proteins were also identified by Chenau et al. in the CM of another NSCLC cell line, 
H358(15). Considering the great heterogeneity in NSCLC and the drastically different MS platforms (isoelectrofocusing-RP-LC-MALDI-MS/MS vs. SCX-RP-LC-ESI-MS/MS), the overlap is substantial. Finally, we used isobaric tagging reagents to quantitatively assess the difference in the secretome among the various normal/NSCLC cells.

Using the abovementioned strategy, we were able to identify proteins that are aberrantly secreted by NSCLC cells. Specifically, a total of 317 proteins are overexpressed in H1993 CM, compared to that from H2073 cells, by at least two-fold (Figure 6A). For example, AGR2 is dramatically upregulated in H1993 cells, compared to that from H2073 and HBEC3-KT cells (Figure 5D). AGR2 is a disulfide isomerase that plays a critical role in maintaining the correct folding of many extracellular proteins(39) and is known to be a secreted protein in mucous and endocrine tissues, including the lungs, stomach, colon and small intestine. AGR2 was first identified in studies focused on differentially expressed genes between estrogen receptor-positive and -negative breast cancers(38). Subsequent studies point to the intriguing possibility that AGR2 might function as an oncogene that promotes cell growth and migration(37). Moreover, AGR2 is overexpressed in many adenocarcinomas, including those of esophagus, pancreas, prostate and lung(33-36). Functional studies have demonstrated that knock-down of AGR2 in esophageal cancer cell lines leads to greatly reduced anchorage-independent growth in a soft agar assay, and tumor growth in a mouse xenograft models(53). Finally, esophageal cancer cells are able to respond to AGR2 in the media, which results in increased migration in a transwell assay.

We selected 12 proteins from this list of 317 upregulated proteins and performed functional characterization (Table. 1). We found that siRNA-mediated knock down of six genes, including SULT2B1, CEACAM5, SPRR3, AGR2, S100P and S100A14, led to reduced migration of H1993 cells (Figure 6B). Remarkably, comprehensive meta-analysis of published transcriptomic data revealed that NSCLC patients whose tumors express higher levels of SULT2B1, CEACAM5, SPRR3, S100P and S100A14, have a worse prognosis.

In addition to furthering our understanding of the relationship between the components of the secretome and the basic biology of NSCLC tumors, simple identification of secreted proteins from either tumor or the tissue microenvironment might serve as powerful diagnostic and prognostic biomarkers. We believe the work outlined here begins to lay the foundations for that necessary eventuality. In terms of lung cancer models, NSCLC is a highly heterogeneous disease with significant differences in both histologic presentation as well as omics level comparisons. Moreover, an "expression signature" that is comprised of a panel of secreted proteins might serve as better biomarkers with improved sensitivity and specificity in disease screening, diagnosis, and monitoring response to therapy. The proteins identified in our study might serve as excellent candidates for this purpose.

\section{Supplementary Material}

Refer to Web version on PubMed Central for supplementary material. 


\section{Acknowledgments}

This work was supported by grants from the UT Southwestern Endowed Scholar Program (Y. Y.), the Cancer Prevention and Research Institute of Texas (CPRIT R1103 to Y.Y. and CPRIT RP110708 to J.D.M.), the Welch Foundation (I-1800 to Y.Y), National Institutes of Health (NIH) (GM114160 to Y. Y.), American Cancer Society (Research Scholar Grant, RSG-15-062-01-TBE and Institutional Research Grant, IRG-02-196-07, to Y. Y.) and University of Texas Specialized Program of Research Excellent in Lung Cancer (NIH CA70907 to J.D.M.). Y. Y. is a Virginia Murchison Linthicum Scholar in Medical Research and a CPRIT Scholar in Cancer Research.

\section{References}

1. Rolfo C, Passiglia F, Ostrowski M, Farracho L, Ondoichova T, Dolcan A, Castiglia M, Remmen R, Papadimitriou K, Pauwels P. Improvement in lung cancer outcomes with targeted therapies: an update for family physicians. J Am Board Fam Med. 2015; 28:124-133. [PubMed: 25567833]

2. Sharma SV, Bell DW, Settleman J, Haber DA. Epidermal growth factor receptor mutations in lung cancer. Nat Rev Cancer. 2007; 7:169-181. [PubMed: 17318210]

3. Cheng H, Shcherba M, Kandavelou K, Liang Y, Liu H, Perez-Soler R. Emerging drugs for squamous cell lung cancer. Expert Opin Emerg Drugs. 2015; 20:149-160. [PubMed: 25557559]

4. Godoy MC, Naidich DP. Subsolid pulmonary nodules and the spectrum of peripheral adenocarcinomas of the lung: recommended interim guidelines for assessment and management. Radiology. 2009; 253:606-622. [PubMed: 19952025]

5. Lynch TJ, Bell DW, Sordella R, Gurubhagavatula S, Okimoto RA, Brannigan BW, Harris PL, Haserlat SM, Supko JG, Haluska FG, Louis DN, Christiani DC, Settleman J, Haber DA. Activating mutations in the epidermal growth factor receptor underlying responsiveness of non-small-cell lung cancer to gefitinib. N Engl J Med. 2004; 350:2129-2139. [PubMed: 15118073]

6. Eberhard DA, Johnson BE, Amler LC, Goddard AD, Heldens SL, Herbst RS, Ince WL, Janne PA, Januario T, Johnson DH, Klein P, Miller VA, Ostland MA, Ramies DA, Sebisanovic D, Stinson JA, Zhang YR, Seshagiri S, Hillan KJ. Mutations in the epidermal growth factor receptor and in KRAS are predictive and prognostic indicators in patients with non-small-cell lung cancer treated with chemotherapy alone and in combination with erlotinib. J Clin Oncol. 2005; 23:5900-5909. [PubMed: 16043828]

7. Upadhyay S, Liu C, Chatterjee A, Hoque MO, Kim MS, Engles J, Westra W, Trink B, Ratovitski E, Sidransky D. LKB1/STK11 suppresses cyclooxygenase-2 induction and cellular invasion through PEA3 in lung cancer. Cancer Res. 2006; 66:7870-7879. [PubMed: 16912160]

8. Soda M, Choi YL, Enomoto M, Takada S, Yamashita Y, Ishikawa S, Fujiwara S, Watanabe H, Kurashina K, Hatanaka H, Bando M, Ohno S, Ishikawa Y, Aburatani H, Niki T, Sohara Y, Sugiyama Y, Mano H. Identification of the transforming EML4-ALK fusion gene in non-small-cell lung cancer. Nature. 2007; 448:561-566. [PubMed: 17625570]

9. Collisson EA. Rb and Prognosis in Resected Lung Adenocarcinoma. Clin Cancer Res. 2015; 21:2418-2420. [PubMed: 25645862]

10. Kemper B, Habener JF, Rich A, Potts JT Jr. Parathyroid secretion: discovery of a major calciumdependent protein. Science. 1974; 184:167-169. [PubMed: 4815723]

11. Burleigh A, McKinney S, Brimhall J, Yap D, Eirew P, Poon S, Ng V, Wan A, Prentice L, Annab L, Barrett J, Caldas C, Eaves C, Aparicio S. A co-culture genome-wide RNAi screen with mammary epithelial cells reveals transmembrane signals required for growth and differentiation. Breast Cancer Res. 2015:17. [PubMed: 25849559]

12. Bruns C, McCaffery JM, Curwin AJ, Duran JM, Malhotra V. Biogenesis of a novel compartment for autophagosome-mediated unconventional protein secretion. J Cell Biol. 2011; 195:979-992. [PubMed: 22144692]

13. Kim YJ, Sertamo K, Pierrard MA, Mesmin C, Kim SY, Schlesser M, Berchem G, Domon B. Verification of the Biomarker Candidates for Non-small-cell Lung Cancer Using a Targeted Proteomics Approach. J Proteome Res. 2015; 14:1412-1419. [PubMed: 25597550]

14. Kulasingam V, Diamandis EP. Proteomics analysis of conditioned media from three breast cancer cell lines: a mine for biomarkers and therapeutic targets. Mol Cell Proteomics. 2007; 6:1997-2011. [PubMed: 17656355] 
15. Chenau J, Michelland S, de Fraipont F, Josserand V, Coll JL, Favrot MC, Seve M. The cell line secretome, a suitable tool for investigating proteins released in vivo by tumors: application to the study of p53-modulated proteins secreted in lung cancer cells. J Proteome Res. 2009; 8:45794591. [PubMed: 19639960]

16. Ramirez RD, Sheridan S, Girard L, Sato M, Kim Y, Pollack J, Peyton M, Zou Y, Kurie JM, Dimaio JM, Milchgrub S, Smith AL, Souza RF, Gilbey L, Zhang X, Gandia K, Vaughan MB, Wright WE, Gazdar AF, Shay JW, Minna JD. Immortalization of human bronchial epithelial cells in the absence of viral oncoproteins. Cancer Res. 2004; 64:9027-9034. [PubMed: 15604268]

17. Sato M, Vaughan MB, Girard L, Peyton M, Lee W, Shames DS, Ramirez RD, Sunaga N, Gazdar AF, Shay JW, Minna JD. Multiple oncogenic changes (K-RAS(V12), p53 knockdown, mutant EGFRs, p16 bypass, telomerase) are not sufficient to confer a full malignant phenotype on human bronchial epithelial cells. Cancer Res. 2006; 66:2116-2128. [PubMed: 16489012]

18. Benedettini E, Sholl LM, Peyton M, Reilly J, Ware C, Davis L, Vena N, Bailey D, Yeap BY, Fiorentino M, Ligon AH, Pan BS, Richon V, Minna JD, Gazdar AF, Draetta G, Bosari S, Chirieac LR, Lutterbach B, Loda M. Met Activation in Non-Small Cell Lung Cancer Is Associated with de Novo Resistance to EGFR Inhibitors and the Development of Brain Metastasis. Am J of Pathol. 2010; 177:415-423. [PubMed: 20489150]

19. Mayba O, Gnad F, Peyton M, Zhang F, Walter K, Du P, Huntley MA, Jiang Z, Liu J, Haverty PM, Gentleman RC, Li R, Minna JD, Li Y, Shames DS, Zhang Z. Integrative analysis of two cell lines derived from a non-small-lung cancer patient--a panomics approach. Pac Symp Biocomput. 2014:75-86. [PubMed: 24297535]

20. Yu YH, Yoon SO, Poulogiannis G, Yang Q, Ma XJM, Villen J, Kubica N, Hoffman GR, Cantley LC, Gygi SP, Blenis J. Phosphoproteomic Analysis Identifies Grb10 as an mTORC1 Substrate That Negatively Regulates Insulin Signaling. Science. 2011; 332:1322-1326. [PubMed: 21659605]

21. Zhang YJ, Wang JQ, Ding M, Yu YH. Site-specific characterization of the Asp- and Glu-ADPribosylated proteome. Nat Methods. 2013; 10:981-984. [PubMed: 23955771]

22. Yu FX, Zhao B, Panupinthu N, Jewell JL, Lian I, Wang LH, Zhao JG, Yuan HX, Tumaneng K, Li HR, Fu XD, Mills GB, Guan KL. Regulation of the Hippo-YAP Pathway by G-Protein-Coupled Receptor Signaling. Cell. 2012; 150:780-791. [PubMed: 22863277]

23. Erickson BK, Jedrychowski MP, McAlister GC, Everley RA, Kunz R, Gygi SP. Evaluating multiplexed quantitative phosphopeptide analysis on a hybrid quadrupole mass filter/linear ion trap/orbitrap mass spectrometer. Anal Chem. 2015; 87:1241-1249. [PubMed: 25521595]

24. Huttlin EL, Jedrychowski MP, Elias JE, Goswami T, Rad R, Beausoleil SA, Villen J, Haas W, Sowa ME, Gygi SP. A tissue-specific atlas of mouse protein phosphorylation and expression. Cell. 2010; 143:1174-1189. [PubMed: 21183079]

25. Delgado O, Kaisani AA, Spinola M, Xie XJ, Batten KG, Minna JD, Wright WE, Shay JW. Multipotent Capacity of Immortalized Human Bronchial Epithelial Cells. Plos One. 2011; 6

26. Sato M, Larsen JE, Lee W, Sun H, Shames DS, Dalvi MP, Ramirez RD, Tang H, Dimaio JM, Gao BN, Xie Y, Wistuba II, Gazdar AF, Shay JW, Kondo M, Hasegawa Y, Minna JD. Human Lung Epithelial Cells Progressed to Malignancy through Specific Oncogenic Manipulations. Mol Cancer Res. 2013; 18:638-650.

27. Puri N, Salgia R. Synergism of EGFR and c-Met pathways, cross-talk and inhibition, in non-small cell lung cancer. J Carcinog. 2008; 7

28. Byron A, Humphries JD, Humphries MJ. Defining the extracellular matrix using proteomics. International Int J of Exp Pathol. 2013; 94:75-92.

29. Singh R, Bandyopadhyay D. MUC1: a target molecule for cancer therapy. Cancer Biol Ther. 2007; 6:481-486. [PubMed: 18027437]

30. Jarrard JA, Linnoila RI, Lee HR, Steinberg SM, Witschi H, Szabo E. MUC1 is a novel marker for the type II pneumocyte lineage during lung carcinogenesis. Cancer Res. 1998; 58:5582-5589. [PubMed: 9850098]

31. Kharbanda A, Rajabi H, Jin C, Tchaicha J, Kikuchi E, Wong KK, Kufe D. Targeting the oncogenic MUC1-C protein inhibits mutant EGFR-mediated signaling and survival in non-small cell lung cancer cells. Clin Cancer Res. 2014; 20:5423-5434. [PubMed: 25189483] 
32. Blumenthal RD, Hansen HJ, Goldenberg DM. Inhibition of adhesion, invasion, and metastasis by antibodies targeting CEACAM6 (NCA-90) and CEACAM5 (Carcinoembryonic antigen). Cancer Res. 2005; 65:8809-8817. [PubMed: 16204051]

33. Fritzsche FR, Dahl E, Dankof A, Burkhardt M, Pahl S, Petersen I, Dietel M, Kristiansen G. Expression of AGR2 in non small cell lung cancer. Histol Histopathol. 2007; 22:703-708. [PubMed: 17455144]

34. Maresh EL, Mah V, Alavi M, Horvath S, Bagryanova L, Liebeskind ES, Knutzen LA, Zhou Y, Chia D, Liu AY, Goodglick L. Differential expression of anterior gradient gene AGR2 in prostate cancer. BMC Cancer. 2010; 10

35. Inoue M, Hiyama K, Nakabayashi K, Morii E, Minami M, Sawabata N, Shintani Y, Nakagiri T, Susaki Y, Maeda J, Higashiyama M, Okami J, Yoshida Y, Ding J, Otomo Y, Okumura M. An accurate and rapid detection of lymph node metastasis in non-small cell lung cancer patients based on one-step nucleic acid amplification assay. Lung Cancer. 2012; 78:212-218. [PubMed: 23026640]

36. Chung K, Nishiyama N, Wanibuchi H, Yamano S, Hanada S, Wei M, Suehiro S, Kakehashi A. AGR2 as a potential biomarker of human lung adenocarcinoma. Osaka City Med J. 2012; 58:1324. [PubMed: 23094510]

37. Wang Z, Hao Y, Lowe AW. The adenocarcinoma-associated antigen, AGR2, promotes tumor growth, cell migration, and cellular transformation. Cancer Res. 2008; 68:492-497. [PubMed: 18199544]

38. Salmans ML, Zhao F, Andersen B. The estrogen-regulated anterior gradient 2 (AGR2) protein in breast cancer: a potential drug target and biomarker. Breast Cancer Res. 2013; 15

39. Norris AM, Gore A, Balboni A, Young A, Longnecker DS, Korc M. AGR2 is a SMAD4suppressible gene that modulates MUC1 levels and promotes the initiation and progression of pancreatic intraepithelial neoplasia. Oncogene. 2013; 32:3867-3876. [PubMed: 22945649]

40. Salman ED, Faye-Petersen O, Falany CN. Hydroxysteroid sulfotransferase 2B1b expression and localization in normal human brain. Horm Mol Biol Clin Invest. 2011; 8:445-454.

41. Ramachandran V, Arumugam T, Wang HM, Logsdon CD. Anterior gradient 2 is expressed and secreted during the development of pancreatic cancer and promotes cancer cell survival. Cancer Res. 2008; 68:7811-7818. [PubMed: 18829536]

42. Schlottmann I, Ehrhart-Bornstein M, Wabitsch M, Bornstein SR, Lamounier-Zepter V. Calciumdependent release of adipocyte fatty acid binding protein from human adipocytes. Int $\mathrm{J}$ Obes. 2014; 38:1221-1227.

43. Chen H, Yuan Y, Zhang C, Luo A, Ding F, Ma J, Yang S, Tian Y, Tong T, Zhan Q, Liu Z. Involvement of S100A14 protein in cell invasion by affecting expression and function of matrix metalloproteinase (MMP)-2 via p53-dependent transcriptional regulation. J Biol Chem. 2012; 287:17109-17119. [PubMed: 22451655]

44. Marhaba R, Klingbeil P, Nuebel T, Nazarenko I, Buechler MW, Zoeller M. CD44 and EpCAM: cancer-initiating cell markers. Curr Mol Med. 2008; 8:784-804. [PubMed: 19075676]

45. Arumugam T, Simeone DM, Schmidt AM, Logsdon CD. S100P stimulates cell proliferation and survival via receptor for activated glycation end products (RAGE). J Biol Chem. 2004; 279:50595065. [PubMed: 14617629]

46. Gyorffy B, Surowiak P, Budczies J, Lanczky A. Online Survival Analysis Software to Assess the Prognostic Value of Biomarkers Using Transcriptomic Data in Non-Small-Cell Lung Cancer. Plos One. 2013; 8

47. Taguchi A, Politi K, Pitteri SJ, Lockwood WW, Faca VM, Kelly-Spratt K, Wong CH, Zhang Q, Chin A, Park KS, Goodman G, Gazdar AF, Sage J, Dinulescu DM, Kucherlapati R, Depinho RA, Kemp CJ, Varmus HE, Hanash SM. Lung cancer signatures in plasma based on proteome profiling of mouse tumor models. Cancer Cell. 2011; 20:289-299. [PubMed: 21907921]

48. Cairns RA, Harris IS, Mak TW. Regulation of cancer cell metabolism. Nat Rev Cancer. 2011; 11:85-95. [PubMed: 21258394]

49. Chang YH, Lee SH, Chang HC, Tseng YL, Lai WW, Liao CC, Tsay YG, Liao PC. Comparative secretome analyses using a hollow fiber culture system with label-free quantitative proteomics 
indicates the influence of PARK7 on cell proliferation and migration/invasion in lung adenocarcinoma. J Proteome Res. 2012; 11:5167-5185. [PubMed: 22985211]

50. Huang LJ, Chen SX, Huang Y, Luo WJ, Jiang HH, Hu QH, Zhang PF, Yi H. Proteomics-based identification of secreted protein dihydrodiol dehydrogenase as a novel serum markers of nonsmall cell lung cancer. Lung Cancer. 2006; 54:87-94. [PubMed: 16876904]

51. Zhang F, Lin H, Gu A, Li J, Liu L, Yu T, Cui Y, Deng W, Yan M, Li J, Yao M. SWATH- and iTRAQ-based quantitative proteomic analyses reveal an overexpression and biological relevance of CD109 in advanced NSCLC. J Proteomics. 2014; 102:125-136. [PubMed: 24667143]

52. Planque C, Kulasingam V, Smith CR, Reckamp K, Goodglick L, Diamandis EP. Identification of five candidate lung cancer biomarkers by proteomics analysis of conditioned media of four lung cancer cell lines. Mol Cell Proteomics. 2009; 8:2746-2758. [PubMed: 19776420]

53. Wang Z, Hao Y, Lowe AW. The adenocarcinoma-associated antigen, AGR2, promotes tumor growth, cell migration, and cellular transformation. Cancer Res. 2008; 68:492-497. [PubMed: 18199544] 

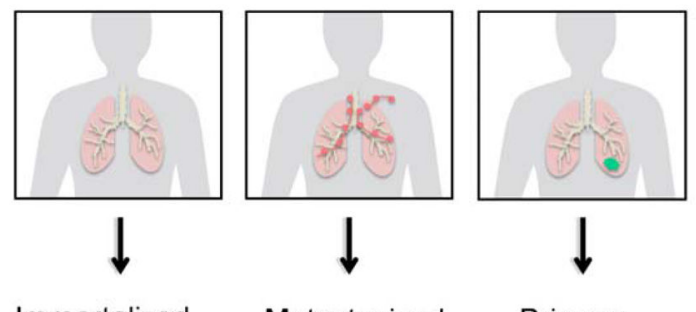

Immortalized epithelial cells

Metastasized NSCLC

Primary
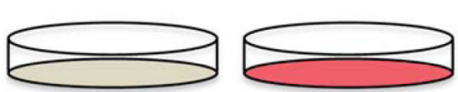

HBEC3KT

H1993

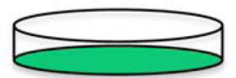

H2O73

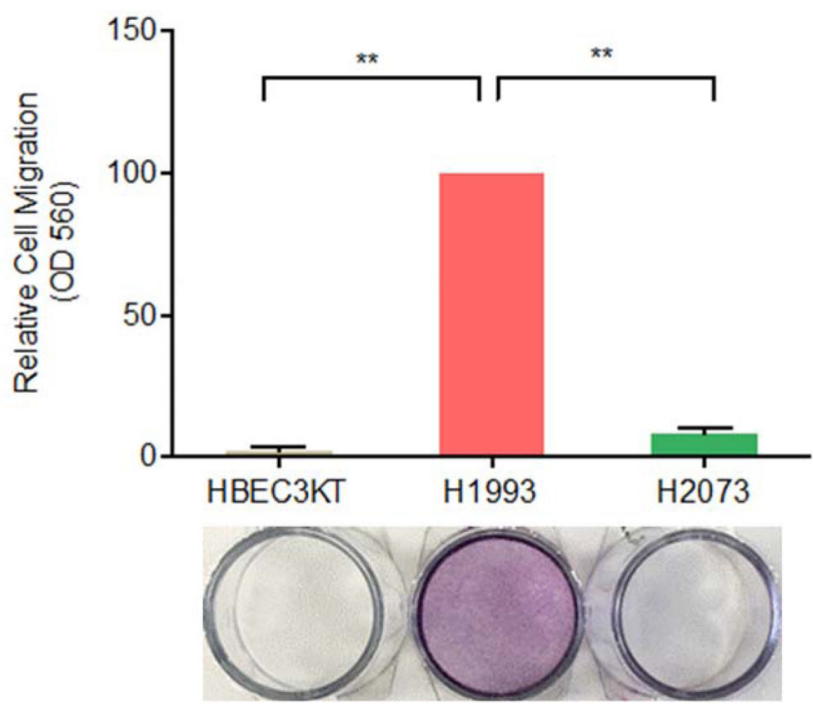

31

Figure 1. H1993 cells are associated with a metastatic phenotype

HBEC3-KT, H1993 and H2073 cells were cultured in serum-free media in the insert of a transwell apparatus. The lower chamber was filled with media containing FBS. After 48 hours, cells migrated through the membrane were stained with crystal violet. The crystal violet was then dissolved with $33 \%$ acetic acid and the absorbance at $560 \mathrm{~nm}$ was measured from three independent experiments $(* *, \mathrm{p}<0.01)$. 
A

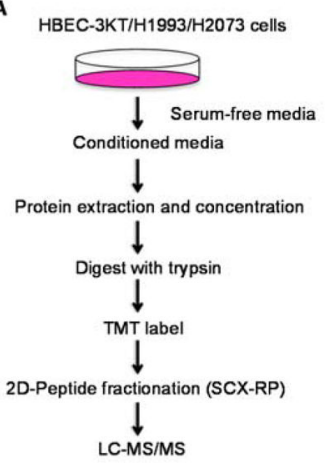

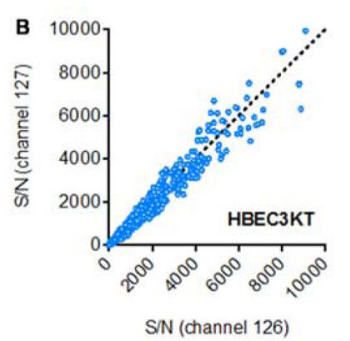
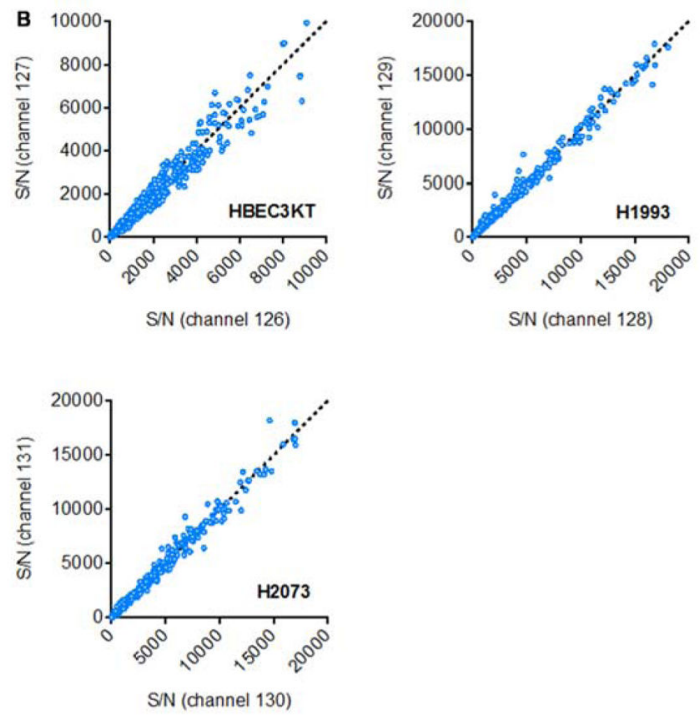

Figure 2. A mass spectrometry-based platform for quantitative secretomic analysis (A) A schematic of the approach. Briefly, proteins were extracted from the CM of HBEC3KT, H1993 and H2073 cells. They were then digested with trypsin, and were labeled with TMT reagents. (B) Two biological replicate experiments were performed for each cell line, i.e. 126 and 127 for HBEC3-KT; 128 and 129 for H1993; 1301 and 131 for H2073. The TMT reporter ion intensity ( $\mathrm{SN}$ ) from all the peptides of a protein is summed, and is plotted for the two biological replicate experiments. 
A

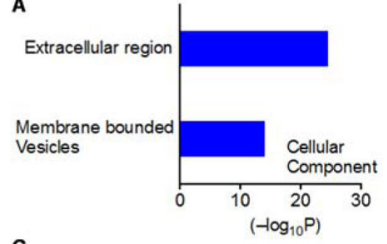

C

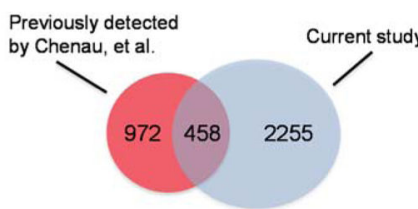

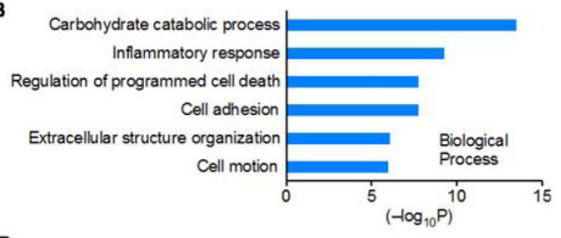

Signal peptide Alpha subunit Beta subunit

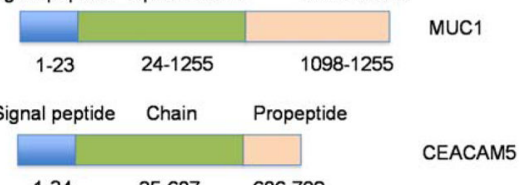

Figure 3. Identification of secreted proteins from normal/NSCLC cells

GO ontology, (A) Cellular Component (CC) and, (B) Biological Processes (BP), analysis of the proteins identified from the CM sample of the three lung cell lines (proteins with a summed TMT ion intensity of at least $10^{4}$ were selected) (C) Cross-reference analysis of the $\mathrm{CM}$ proteins identified from a previous study (Chenau et al., H358 cells) and the current study. (D) Examples of CM proteins that were uniquely identified in the CM from HBEC3KT/H1993/H2073 cells. These two proteins (MUC1 and CEACAM5) both harbor an Nterminal signal peptide. 


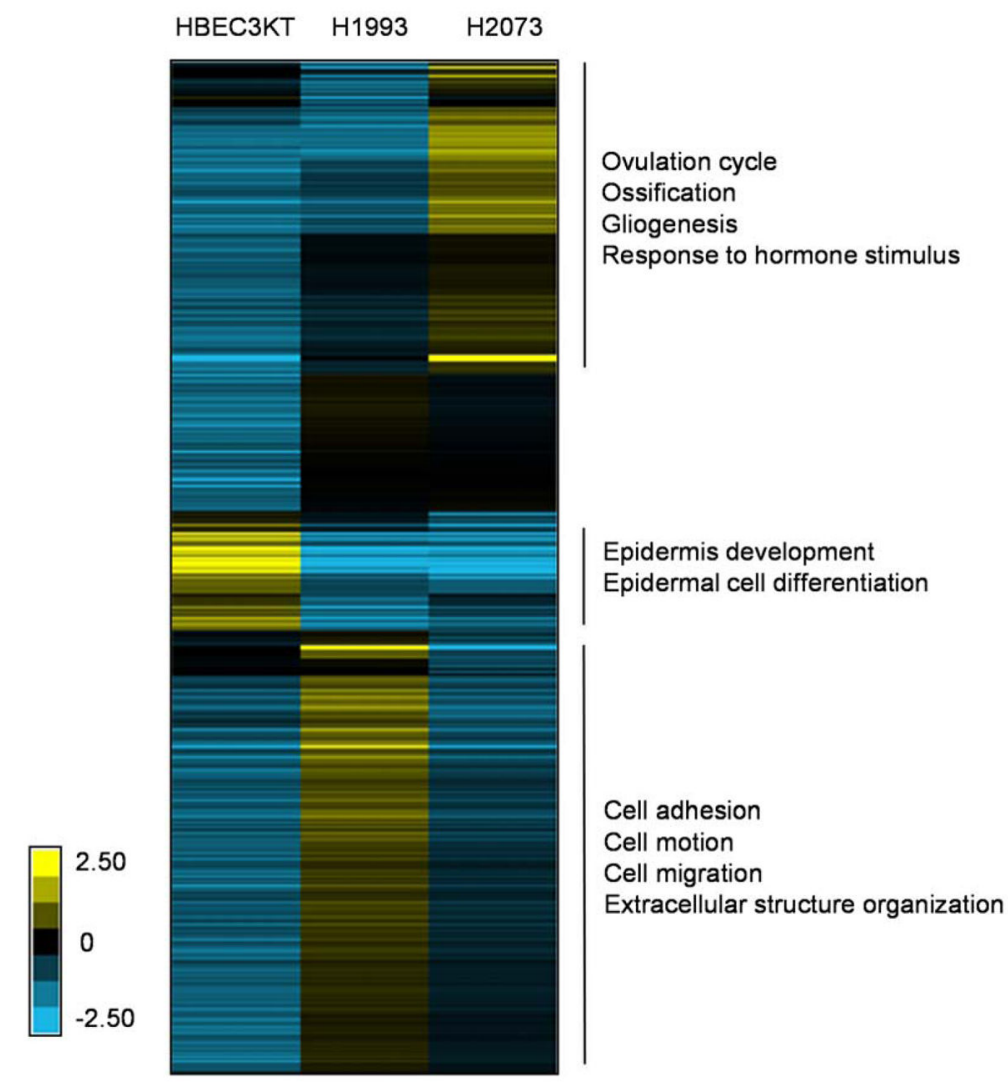

Figure 4. Comparative expression analysis of proteins in CM from HBEC3-KT/H1993/H2073 cells

CM Proteins overexpressed in one cell line, compared to the other two were extracted and were subject to GO Biological Process (BP) analysis. 
A
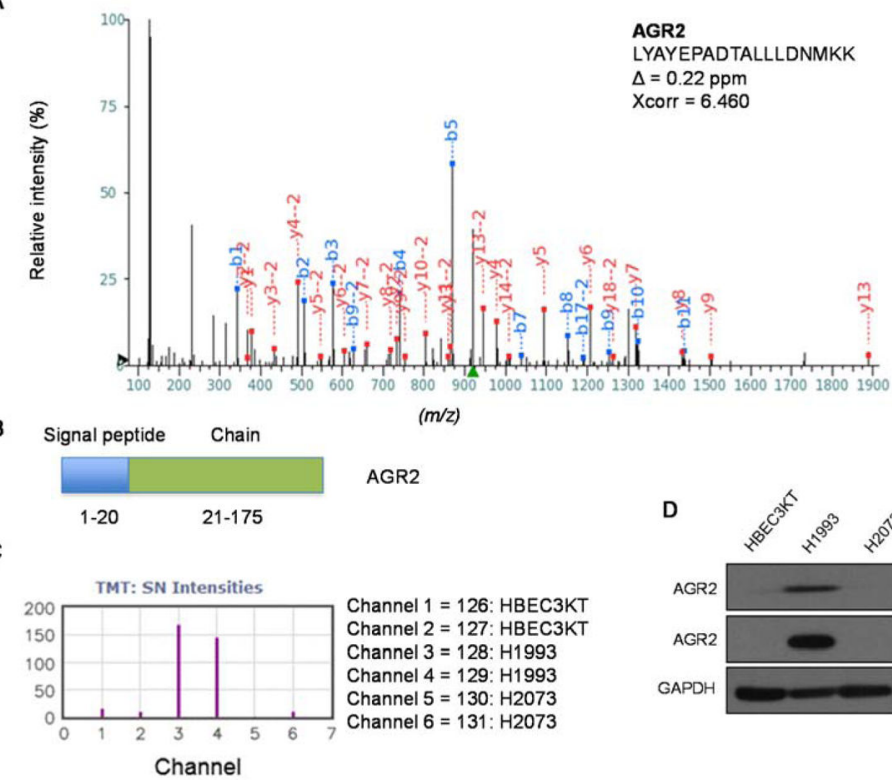

D

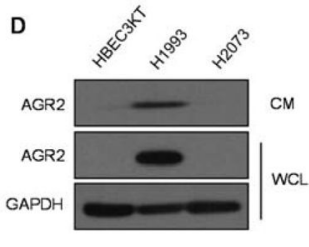

Figure 5. The CM from H1993 cells contains high levels of AGR2

(A) Identification of an AGR2 peptide by HCD tandem mass spectrometry. Assigned $b$-and $y$ - ions are highlighted in blue and red, respectively. (B) Domain structure of AGR2. (C)

Extracted TMT report ions for the AGR2 peptide identified in (A). (D) Independent immunoblotting experiments confirm that the CM from H1993 cells contains high levels of AGR2. 


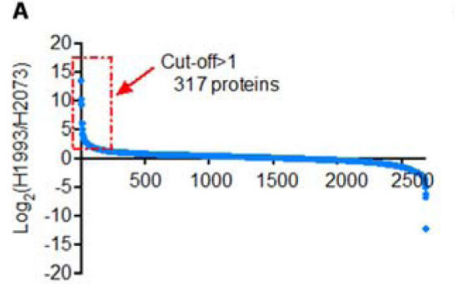

C

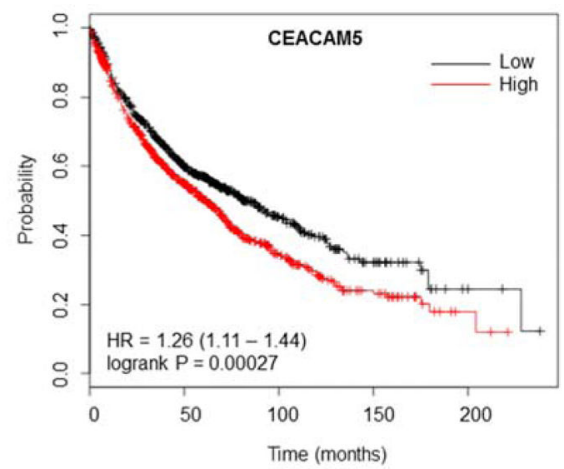

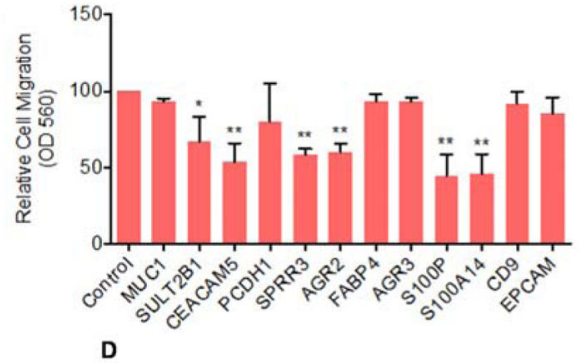

Figure 6. Secreted proteins modulate the metastatic phenotype of $\mathrm{H} 1993$ cells

(A) Secreted proteins that are overexpressed in H1993 CM (by more than 2 fold), compared to $\mathrm{H} 2073$ cells. CM protein abundance of these two lines as determined in Figure 2 was extracted, and were plotted on a $\log 2$ scale. (B) H1993 cells were transfected with the indicated siRNAs, and cell migration was measured in a transwell assay $(n=3){ }^{*}, \mathrm{p}<0.05$; **, p<0.01. (C) Kaplan Meier Plots (overall survival) of 1926 NSCLC patients for the expression for CEACAM5 (C) and SPRR3 (D). 


\section{Table 1}

A list of representative proteins that are overexpressed in H1993 CM. These proteins were selected for further functional analysis.

\begin{tabular}{ccccc}
\hline \multicolumn{5}{c}{ S/N ( sum) } \\
\hline Gene Symbol & HBEC3KT & H1993 & H2073 & H1993/H2073 \\
\hline SPRR3 & 57 & 522 & 46 & 11.4 \\
MUC1 & 33 & 706 & 63 & 11.2 \\
SULT2B1 & 39 & 832 & 101 & 8.3 \\
PCDH1 & 2530 & 5790 & 715 & 8.1 \\
FABP4 & 220 & 3283 & 442 & 7.4 \\
S100A14 & 790 & 1276 & 178 & 7.2 \\
CEACAM5 & 211 & 689 & 111 & 6.2 \\
AGR2 & 2426 & 9237 & 1547 & 6.0 \\
AGR3 & 42 & 473 & 83 & 5.7 \\
CD9 & 778 & 2963 & 788 & 3.8 \\
EPCAM & 303 & 3104 & 869 & 3.6 \\
S100P & 152 & 1920 & 691 & 2.8 \\
\hline
\end{tabular}

